\title{
Simulação da Hidrodinâmica do Mancal de Deslizamento através do Método dos Elementos de Contorno
}

\section{Carlos Friedrich Loeffler ${ }^{1}$}

Programa de Pós Graduação em Engenharia Mecânica, PPGEM/UFES, Vitória, ES

\section{Cleivisson Allan Santos de Sousa ${ }^{2}$}

Departamento de Engenharia Mecânica CT/UFES, Vitória, ES.

\author{
Filipe Ribeiro dos Santos ${ }^{3}$
}

Departamento de Engenharia Mecânica CT/UFES, Vitória, ES.

Resumo. O Método dos Elementos de Contorno é uma técnica numérica eficiente, que vem conquistando interesse cada vez maior no meio acadêmico e industrial. Apresenta grandes vantagens no trato de problemas com fronteiras móveis, concentração de tensões, fratura, contato, meios infinitos e semi-infinitos e outros casos em que as técnicas de domínio não são adequadas nem simples de empregar. Algumas deficiências na solução de problemas que incluem de fontes, sorvedouros, forças de inércia e outras ações similares têm sido superadas por novas estratégias, como a formulação que faz a integração no contorno das funções de interpolação auxiliares (MECID), aproximando adequadamente ações de domínio generalizadas. Nesta pesquisa, aplica-se a MECID para gerar a distribuição de pressão ao longo da superfície de contato de um mancal hidrodinâmico. A conformação geométrica das superfícies pode ser qualquer, mas para ilustrar a aplicabilidade e precisão do método, apresenta-se um exemplo unidimensional simples, com variação linear da camada de lubrificante.

Palavras-chave. Mancal Hidrodinâmico, Elementos de Contorno, Funções de Base Radial.

\section{Equação de Governo}

A equação diferencial de equilíbrio para o caso unidimensional é a seguinte [3]:

$$
\frac{\partial^{2} \mathrm{P}}{\partial \mathrm{x}^{2}}+\frac{3}{\mathrm{~h}} \frac{\mathrm{dh}}{\mathrm{dx}} \frac{\partial \mathrm{P}}{\partial \mathrm{x}}=-6 \mu V \frac{\mathrm{dh}}{\mathrm{dx}}
$$

$\mathrm{V}$ é uma velocidade média na seção entre o mancal e o rotor e $\mu$ é a viscosidade. A variável $\mathrm{h}(\mathrm{x})$ depende da forma das superfícies examinadas, mas é conhecida. As condições

1'carlosloeffler@bol.com.br

${ }^{2}$ cleivisson.allan@gmail.com

${ }^{3}$ filipers14@gmail.com 
essenciais são dadas pela pressão inicial de injeção do óleo $\mathrm{P}(\mathrm{x})$ e as naturais pelo fluxo $\mathrm{q}(\mathrm{x})$ :

$\mathrm{q}(\mathrm{x})=\rho \mathrm{h}(\mathrm{x}) \mathrm{v}(\mathrm{x}), \quad \mathrm{v}(\mathrm{x})=\mathrm{v}-\frac{\mathrm{h}^{2}(\mathrm{x})}{\mu} \frac{\mathrm{dh}(\mathrm{x})}{\mathrm{dx}} \frac{\partial \mathrm{P}(\mathrm{x})}{\partial \mathrm{x}}$

O modelo de elementos de contorno usa a técnica Quase Dual para tratar o termo da derivada primeira da pressão e a formulação MECID [2] para aproximar o lado direito da equação (1). Ambas as técnicas transformam integrais de domínio em integrais de contorno. Elementos lineares aproximam pressões e velocidades e funções radiais de placa fina fazem interpolações auxiliares. Embora a equação diferencial de governo seja unidimensional e seja possível a obtenção de soluções analíticas, a aplicação do MEC torna acessível introduzir diferentes condições de contorno e alterar a conformação geométrica das superfícies.

\section{Exemplo de Aplicação}

Resolveu-se um domínio linear de comprimento unitário com variação linear da altura $\mathrm{h}(\mathrm{x})$ e pressão nula na entrada e na saída [1]. Os valores numéricos da pressão ao longo do domínio são mostrados no quadro (a) da figura 1, enquanto no quadro (b) mostra-se o perfil obtido analiticamente. Os resultados apresentam excelente concordância neste caso simples.

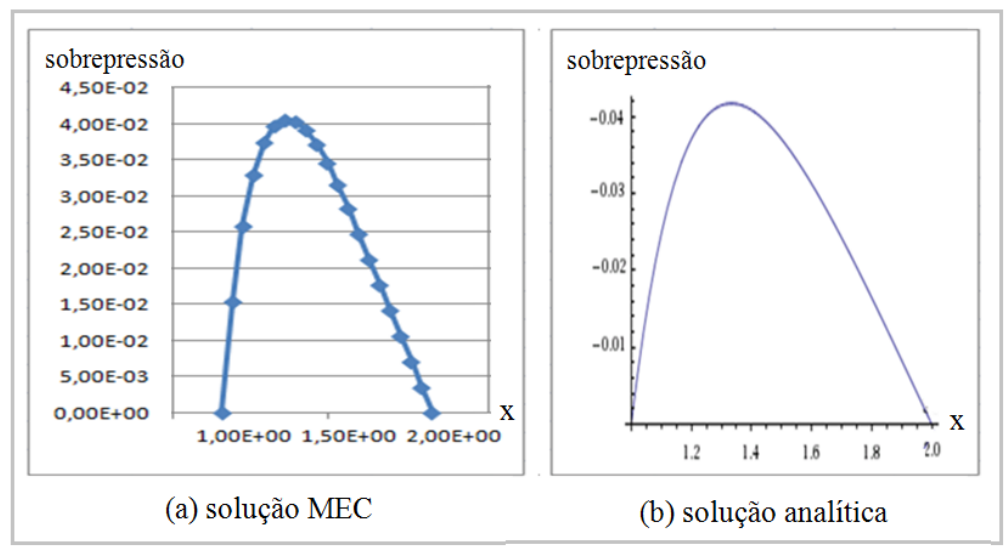

Figura 1: Valores da sobrepressão ao longo do domínio

\section{Referências}

[1] D. D. Júnior, Tribologia, Lubrificação e Mancais de Deslizamento, vol. único, Ciência Moderna, (2005).

[2] C. F. Loeffler, A.L. Cruz and A. Bulcão, A Direct Use of Radial Basis Interpolation Functions for Modelling Source Terms with the Boundary Element Method, EABE, (2014) DOI: 10.1016/j.enganabound.2014.07.007.

[3] M. F. Spotts, Design of Machine Elements, Prentice-Hall, New York, (1961). 